\title{
st \\ Voltaire e Algarotti: divulgadores da óptica de Newton na Europa do século xviII
}

\author{
Breno Arsioli Moura \\ Gibelle Gelestino Silva
}

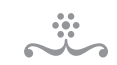

\section{RESUMO}

No início do século xvıII, Isaac Newton publicou seu principal trabalho sobre óptica, o Opticks (Óptica). Impregnado por uma perspectiva indutiva, o livro logo se tornou a principal referência para os estudos sobre a luz e as cores, sendo amplamente popularizado pelos seguidores de Newton. Neste artigo, analisamos como dois importantes livros contribuíram para essa popularização e também qual era a imagem de ciência que tencionavam propagar, o Élements de la philosophie de Newton (Elementos da filosofia de Newton) de Voltaire e o Newtonianismo perle dame (Newtonianismo para as damas) de Algarotti. Será possível perceber que ambos os autores distorceram o conteúdo do livro de Newton, no intuito de propagar uma imagem idealizada das ideias newtonianas e da própria filosofia natural.

Palavras-ghave • Newton. Voltaire. Algarotti. Óptica. Século xviII. Divulgação científica.

\section{INTRODUÇÃO}

Isaac Newton (1643-1727) trabalhou em diversas áreas e abordou assuntos variados, desde seus conhecidos estudos sobre a mecânica e a óptica até os ainda pouco explorados estudos sobre a alquimia e a religião (cf. McGuire \& Rattansi, 1966; Dobbs, 1982). A partir das pesquisas sobre a luz e as cores realizadas entre as décadas de 1660 e 1690 , Newton redigiu trabalhos importantes, até hoje apreciados como exemplares da prática experimental (cf. Cohen, 2002). A principal obra contendo seus estudos sobre a luz é o livro Óptica, publicado pela primeira vez em 1704.

No período recente, a óptica newtoniana tem sido frequentemente estudada, o que trouxe à tona aspectos sobre a metodologia utilizada por Newton que não aparecem de forma explícita em seus escritos e que, muitas vezes, contradizem o que o próprio filósofo natural inglês defendia (cf. Buchwald \& Cohen, 2001). Newton valeu-se extensivamente do uso de hipóteses e especulações, entre elas o uso da concepção cor- 
puscular para a luz. Além disso, uma análise cuidadosa do Óptica e outros trabalhos indica que ele propôs explicações diferentes para os mesmos fenômenos, nem sempre chegando a uma resposta clara e definitiva (cf. Silva, 1996; Shapiro, 2002; Moura, 2008).

No início do século xviII, surgiram diversos trabalhos de seguidores de Newton que buscaram estabelecer uma abordagem mecânica para a óptica. Dentre eles destacam-se as obras de John Desaguliers (1683-1744), George Cheyne (1671-1743), Wilhelm Jacob ‘sGravesande (1688-174,2), Robert Smith (1689-1768) e John Rowning (c.17011771). No território britânico, esses textos foram importantes para consolidar a óptica enquanto um ramo da dinâmica, bem como para fortalecer a imagem de Newton como um modelo de filósofo natural a ser seguido na época (cf. Cantor, 1983, p. 32-42; Hall, 1993, p. 192-3). Seus seguidores, entretanto, ativeram-se apenas àquelas partes da óptica newtoniana que podiam servir como base para uma teoria mecânica da luz e que valorizavam o caráter indutivista da filosofia natural (cf. Cantor, 1983, p. 42). Por exemplo, no caso do Óptica, basicamente apenas o conteúdo do primeiro livro e as "Questões" (Queries) do terceiro livro tornaram-se conhecidos pelo público. Enquanto o primeiro continha um grande número de experimentos, realçando o caráter indutivista, as "Questões" incluíam as especulações de Newton sobre a natureza corpuscular da luz e sua interação com a matéria por meio de forças agindo a distância. Esses foram os elementos principais que fomentaram a construção da concepção corpuscular para a luz defendida ao longo do século xviII. Por sua vez, o conteúdo do segundo livro, que tratava do fenômeno dos anéis coloridos em filmes finos e da teoria dos estados da luz, foi praticamente ignorado, dado que seu conteúdo não se enquadrava de forma coerente na concepção mecânica da luz (cf. Moura \& Silva, 2010).

$\mathrm{Na}$ Europa continental, a óptica newtoniana percorreu caminhos um pouco distintos. Em Portugal, por exemplo, apenas após a segunda metade do século xviII as teorias de Newton começaram a ser ensinadas nas universidades (cf. Bernardo, 1998). Na Alemanha, sua aceitação e recepção foram tímidas nesse período, embora poucas críticas também tenham surgido (cf. Hakfoort, 1995, p. 19-26). Na França e na Itália, ganhou importantes canais de divulgação para um público leigo com as obras de Voltaire (16941778), principalmente no livro Elementos da filosofia de Newton (1996) e no livro O newtonianismo para as damas (1737) de Francesco Algarotti (1712-1764). Essas obras foram determinantes porque se configuravam como fonte para que a elite intelectual leiga na filosofia natural pudesse ter contato com as realizações de Newton, além de inspirar muitos autores do período. Esses livros tornaram-se bastante populares tanto nos países de origem de seus autores quanto no restante do continente europeu. Com isso, colaboraram para diminuir a influência de outras teorias para a luz - a cartesiana, por exemplo-, abrindo caminho para que a óptica newtoniana fosse inicialmente incorporada à filosofia natural francesa e italiana e, posteriormente, à europeia como um todo. 
Neste artigo, analisamos alguns aspectos mais relevantes dessas duas obras. Por um lado, será possível perceber como esses dois autores seguiram a tendência do período, ao selecionarem apenas algumas partes da óptica newtoniana e omitirem outras, no intuito de favorecer suas defesas da concepção corpuscular da luz e suas críticas às concepções concorrentes. Por outro lado, o estudo dessas obras é particularmente importante, pois mostra como certos aspectos da obra newtoniana foram popularizados fora das ilhas britânicas, muitas vezes em contextos nos quais o cartesianismo era dominante.

Ao analisarmos as obras de Voltaire e Algarotti, faremos paralelos com o conteúdo do Óptica, a fim de que o leitor tenha em mãos uma comparação entre os discursos desses autores e o de Newton. A escolha desse livro mostra-se adequada, uma vez que dentre seus textos anteriores, apenas o artigo "Nova teoria da luz e da cores" (1672) e as cartas trocadas com outros filósofos naturais eram conhecidos por algumas pessoas fora da Grã-Bretanha ou do círculo da Royal Society de Londres. Além disso, representavam os pensamentos iniciais de um Newton ainda desconhecido da comunidade de filósofos naturais da época, que sofreriam modificações com o passar dos anos. O Óptica, por sua vez, foi publicado em um contexto no qual Newton era conhecido e prestigiado por seus pares e reuniu suas concepções maduras sobre a natureza da luz e das cores. O sucesso do livro foi imediato não somente nas ilhas britânicas, mas também no continente europeu. Entre 1704 e 1730, o livro teve quatro edições em inglês; em 1706 e 1719, duas edições em latim; em 1720 e 1721, duas edições em francês (cf. Hall, 1993, p. 236-7).

A análise do conteúdo dos livros de Voltaire e Algarotti e sua comparação com o Óptica visa mostrar que, embora os trabalhos de Newton fossem bastante complexos do ponto de vista conceitual e metodológico, essa complexidade foi praticamente ignorada por Voltaire e Algarotti, que selecionaram os conteúdos acessíveis ao grande público e priorizaram os aspectos experimentais da obra. Utilizando essa estratégia, uma imagem idealizada do legado newtoniano foi construída e propagada, enfatizando somente algumas de suas conquistas científicas em detrimento de uma visão mais complexa da obra de Newton. ${ }^{\mathbf{1}}$

\footnotetext{
1 Cabe ainda destacar e justificar duas decisões de cunho metodológico que adotamos neste artigo. Buscamos mostrar como Voltaire e Algarotti popularizaram uma óptica diferente daquela presente no Óptica e não propriamente analisar em detalhes a estrutura dessa óptica, exceto em pontos que julgamos ser necessário. Além disso, o leitor observará que a seção que compreende a obra de Voltaire contém mais comparações ao conteúdo do Óptica do que a seção sobre Algarotti, principalmente nas discussões sobre a existência de uma força de atração entre a luz e os corpos. Optou-se por não repetir as citações do Óptica na análise do texto de Algarotti para manter a fluidez da argumentação.
} 


\section{0 texto de Voltaire sobre Newton}

Voltaire, batizado como François Marie Arouet, nasceu em 21 de novembro de 1694, em uma época na qual o cartesianismo predominava na França. Perto dos $3 \circ$ anos, estabeleceu-se como poeta e dramaturgo, principalmente pelo sucesso de obras como Oedipe e Henriade (cf. Turnovsky, 2009). Após uma briga com um nobre francês, Voltaire autoexilou-se em Londres entre 1726 e 1729, quando teve a oportunidade de acompanhar a grande comoção pela morte de Newton em 1727. Na Inglaterra, ele também vivenciou a liberdade e a valorização dos filósofos naturais e pensadores (cf. Gillispie, 2007 , p. 2566). Fatores como esses fizeram com que Voltaire adquirisse uma aversão pela França e buscasse cada vez mais exaltar a Inglaterra em detrimento de seu país natal. Um dos campos de atuação escolhido por Voltaire foi a filosofia natural, o que o levou, juntamente com motivos científicos e filosóficos, a defender a visão de mundo newtoniana ao invés dos turbilhões de Descartes.

Nas primeiras décadas do século xvıII, a aceitação da filosofia natural newtoniana ainda era restrita às ilhas britânicas. Na França, os obstáculos foram ainda maiores. As teorias cartesianas, mesmo criticadas, dominavam os círculos de discussões dos filósofos naturais da época. Em relação à óptica, mais especificamente, o tema parecia esgotado no país e não havia razão aparente para aceitar uma nova teoria, tal qual a de Newton. Christian Huygens (1629-169o), que em 1690 publicara seu Tratado da luz, contendo uma concepção vibracional para a luz, havia retornado da França para a Holanda pouco antes de sua morte, sem deixar aparentemente seguidores de sua óptica (cf. Hall, 1993, p. 201). Por sua vez, os estudos sobre a luz e as cores de Edme Mariotte (c.1620-1684), surgidos no início da década de 1680, ainda exerciam certa influência na filosofia natural francesa, mas poucos pareceram importar-se com o assunto nos anos seguintes. ${ }^{2}$ No início do século xvıII, destacou-se a leitura de uma tradução parcial do Óptica na Académie des Sciences de Paris em 1706 e 1707, feita por ÉtienneFrançois Geoffroy $(1672-1731)$, e a confirmação dos experimentos com prismas feita por Desaguliers em 1716, a pedido do próprio Newton (cf. Desaguliers, 1716a; 1716b; Hall, 1993, p. 201-4). Foi nesse cenário de poucos questionamentos das ideias vigentes sobre óptica e de certa incredulidade em relação às teorias newtonianas que Voltaire devotou-se a defendê-las.

2 Em meados de 1679, Mariotte reproduziu os experimentos de Newton presentes no artigo "Nova teoria da luz e das cores", publicado em 1672 nas Philosophical Transactions da Royal Society. Mariotte refutou a ideia de Newton de que as cores seriam propriedades originais da luz, uma vez que não observou os mesmos resultados experimentais discutidos no artigo de Newton. As conclusões de Mariotte pareceram determinantes para os filósofos naturais franceses da época, contribuindo para a demora na aceitação das teorias newtonianas da luz e das cores na França (cf. Guerlac, 1981, p. 98-100). 
As primeiras manifestações de Voltaire sobre a Inglaterra e a superioridade dos ingleses foram publicadas em 1733 em suas Cartas sobre a nação inglesa. ${ }^{3}$ No ano seguinte, as cartas foram publicadas em francês, sob o título Cartas filosóficas (Lettres philosophiques) ou Cartas sobre os ingleses (Lettres sur les Anglais) (cf. Gillispie, 2007, p. 2566). Em uma das cartas, intitulada "Sobre Descartes e Sir Isaac Newton", Voltaire compara os feitos de Descartes e Newton, não escondendo sua preferência por este último. Segundo ele, enquanto na França ainda se acreditava que a pressão da Lua causava as marés, na Inglaterra acreditava-se nos efeitos gravitacionais mútuos entre a Lua e a Terra. Da mesma forma, enquanto os cartesianos defendiam que a luz existia no próprio ar, os newtonianos afirmavam que ela vinha do Sol. "Quão curiosamente contraditórias são essas opiniões!”, escreveu Voltaire (1733, p. 96).

O francês prosseguiu deixando claro que o principal problema de Descartes foi seu uso excessivo da imaginação e de hipóteses, considerando-o como alguém levado a especular em demasia porque estava mergulhado em uma França ainda não iluminada pelo indutivismo baconiano. Descartes teria saído da França em busca da verdade, que era então perseguida pela "miserável filosofia das escolas" (cf. Voltaire, 1733, p. 98), parecendo referir-se a escolas filosóficas como o aristotelismo e o platonismo que predominaram no período anterior.

De acordo com Voltaire, enquanto a vida de Descartes havia sido uma sucessão de tristezas, a vida de Newton, pelo contrário, havia sido uma coleção de momentos alegres e festivos. Voltaire escreveu sobre o inglês que ele "foi de uma peculiar felicidade, não somente por ter nascido em um país de liberdade, mas também em uma época em que todas as impertinências escolásticas foram banidas do mundo" (Voltaire, 1733, p. 100). Embora reconhecesse a importância de Descartes, ele notavelmente buscou exaltar Newton e suas realizações.

Este famoso Newton, este destruidor do sistema cartesiano, morreu em março, ano de 1727. Seus compatriotas o honraram durante sua vida e o enterraram como se fosse um rei que fez seu povo feliz (Voltaire, 1733, p. 96).

A exaltação a Newton continuou em sua próxima obra, Elementos da filosofia de Newton, publicado em francês em 1738 e que fez grande sucesso na França e na Europa em geral, sendo traduzido para o alemão, o italiano e o inglês (cf. Casini, 1995, p. 100).

A elaboração do Elementos começou por volta de 1734, quando Voltaire mudouse para o castelo de Émilie le Tonnelier de Breteuil (1706-1749) - a Marquesa de Châtelet-, em Cirey, leste da França. Nesse período, Voltaire dedicou-se a estudar as ideias 
científicas de Newton, embora suas principais fontes fossem obras de seus popularizadores, tais como Henry Pemberton (1694-1771) e 'sGravesande (cf. Casini, 1995, p. 86). Além disso, a convivência com a Marquesa du Châtelet proporcionou a Voltaire um aprendizado sofisticado sobre a mecânica newtoniana, uma vez que ela era uma das mais proeminentes filósofas naturais francesas da época e tradutora do Principia de Newton para o francês (cf. Gjersten, 1986, p. 104; Badinter, 2003).

Voltaire não escreveu o Elementos com a intenção de que seus leitores reproduzissem os experimentos newtonianos. Seu livro não intencionava ser um manual didático ou científico, como os de 'sGravesande ou Smith (cf. Hall, 1993, p. 277), mas estava voltado para um público leigo na filosofia natural, que não compreendia a difícil argumentação matemática do Principia ou a complexa sequência de experimentos do Óptica, o qual, embora tenha sido publicado em inglês e com uma linguagem mais fácil que o Principia, não deixou de ser uma obra voltada a especialistas, pois a argumentação de Newton era sofisticada e, em muitas partes, obscura e complexa.

Colocaremos estes Elementos ao alcance daqueles que só conhecem de nome Newton e a filosofia. A ciência da natureza é um bem que pertence a todos os homens. Todos gostariam de conhecê-lo, poucos têm o tempo ou a paciência de calculá-lo; Newton o fez por eles (Voltaire, 1996 [1738], p. 16).

Nesse mesmo prólogo, Voltaire exalta o caráter esclarecedor e inovador da filosofia natural newtoniana quando comparada com a ignorância de seus antecessores.

Até o presente, a filosofia de Newton, para muitas pessoas, pareceu quase tão ininteligível quanto a dos antigos. Mas a obscuridade dos gregos vinha do fato de que eles, realmente, não possuíam luzes, e as trevas de Newton vêm do fato de que sua luz estava muito longe de nossos olhos. Ele encontrou verdades, mas descobriuas e colocou-as em um abismo. É preciso descer nesse abismo e trazer essas verdades para a luz do dia (Voltaire, 1996 [1738], p. 16).

As interpretações de Voltaire das ideias newtonianas sobre a luz e as cores foram apresentadas na segunda parte do Elementos, intitulada "Física newtoniana". 4 Nela, o filósofo francês aborda essencialmente questões básicas da óptica, tais como a refração, a reflexão, a visão, o arco-íris etc. Inicia comentando sobre a natureza da luz, critican-

4 Na primeira parte, intitulada "Metafísica", Voltaire aborda questões como a existência de Deus, a liberdade, a religião, a natureza da matéria, entre outras. A terceira parte, sem título, está dedicada à discussão do sistema de mundo newtoniano. 
Voltaire e Algarotti: divulgadores da óptiga de Newton na Europa do século xviit

do duramente os gregos, chamados por ele de "mestres da ignorância, pagos pelo povo" (Voltaire, 1996 [1738], p. 69). Da mesma forma, não poupou críticas a Descartes.

Que se vejam finalmente a quantos erros Descartes foi arrastado por esse sistema. Ele não havia feito nenhuma experiência. Imaginava: não examinava este mundo. Criava um outro. Newton, ao contrário, Roemer, Bradley etc. não fizeram senão experiências, e só julgaram segundo os fatos (Voltaire, 1996 [1738], p. 75).

Para Voltaire, a ausência do uso da experimentação para a construção dos modelos cartesianos parece ter sido um fator determinante para o insucesso e incapacidade dessas ideias explicarem satisfatoriamente a natureza da luz. Em trechos posteriores, ele também critica Nicolas Malebranche (1638-1715), filósofo natural francês adepto do cartesianismo e influente nos estudos em óptica na França do início do século xvıII (cf. Hankins, 1967; Hall, 1993, p. 201-3).

O padre Malebranche, que, examinando os erros dos sentidos, não ficou isento daqueles que podem ser causados pela sutileza do gênio, adotou sem prova os três elementos de Descartes, mas mudou muitas coisas neste castelo encantado, e, fazendo ainda menos experiências do que Descartes, fez, tal como ele, um sistema (Voltaire, 1996 [1738], p. 76).

Esse tipo de crítica é recorrente no texto de Voltaire, tanto ao discutir as teorias cartesianas quanto qualquer outra que não as newtonianas. Para Voltaire, um dos fatores que tornavam as ideias de Newton superiores às demais era o uso extensivo da experimentação e sua defesa do método indutivo. 5 Após criticar Descartes a partir de uma perspectiva metodológica, Voltaire passa a discutir aspectos conceituais relacionados à natureza da luz. Na época da publicação do Elementos, era comum associar a luz ao fogo, bem como à eletricidade, visto que esses fenômenos apresentavam propriedades semelhantes. Baseando-se nisso, Voltaire apresentou uma definição para a luz.

O que é, enfim, a matéria da luz? É o próprio fogo, que queima a uma pequena distância quando suas partes são menos tênues, ou mais rápidas, ou mais unidas,

5 Embora Newton tenha defendido explicitamente o uso do método indutivo para compor sua óptica, os métodos utilizados por ele no Óptica e em outras obras foram diversos. A questão sobre o "método newtoniano" é complexa, mas cabe dizer que Newton utilizou hipóteses como parte importante de seus trabalhos e que a visão comum de que ele foi um modelo para o uso do método indutivo é inadequada (cf. Chaudhury, 1962; Palter, 1970; Cohen, 2002; Smith, 2001; Moura \& Silva, 2008). 
e que ilumina docemente nossos olhos quando age de mais longe, quando suas partículas são mais finas, menos rápidas e menos unidas (Voltaire, 1996 [1738], p. 77 ).

Voltaire concebe a luz como composta de partículas de fogo. No Óptica, contudo, Newton não havia apresentado essa definição. O inglês foi cauteloso ao referir-se à natureza da luz, evitando defini-la fisicamente. Utilizou o termo "raio de luz", entendido como "as partes mínimas da luz e as que tanto são sucessivas nas mesmas linhas como simultâneas em várias linhas" (Newton, 1996 [1704], p. 39). Nas "Questões" do terceiro livro do Óptica, Newton abordou explicitamente essa questão, contudo, colocando-a de forma especulativa. "Não seriam os raios de luz corpúsculos minúsculos emitidos pelas substâncias que brilham?" (Newton, 1996 [1704], p. 271).

É bem sabido que Newton procurava não se envolver em polêmicas, principalmente relacionadas à natureza da luz. As polêmicas já tinham lhe causado um enorme incômodo em 1672, após a publicação de seu primeiro artigo, o "Nova teoria da luz e das cores", no qual propôs que a luz branca do sol fosse uma mistura heterogênea de raios coloridos, contrapondo a concepção usualmente aceita na época de que ela seria simples e homogênea. Criticado por diversos filósofos coetâneos que o acusaram injustamente de defender nesse trabalho a natureza corpuscular da luz, no Óptica, Newton continuou a abster-se de defender explicitamente uma concepção particular para a luz, ao contrário do que geralmente se acredita (cf. Silva \& Martins, 1996; Shapiro, 2002).

A diferença entre as definições de Voltaire e Newton para a natureza da luz evidencia uma característica peculiar dos newtonianos do século xvıı. O fato de selecionarem e fazerem modificações e distorções no conteúdo das obras de Newton, transformando partes de sua argumentação, a fim de mostrar que ele, desde o princípio, defendeu abertamente a materialidade da luz e sua interação com os corpos a partir de forças (cf. Cantor, 1983; Silva \& Moura, 2012).

Após discutir a natureza da luz, Voltaire aborda a reflexão e a refração. Defende que a primeira não seria causada pelo choque dos raios de luz na superfície dos corpos, como se poderia intuitivamente acreditar. Para Voltaire, do mesmo modo que os corpos se atraíam entre si, segundo a mecânica newtoniana, a luz, sendo um corpúsculo, também interagiria com outros corpos por meio de uma força atrativa.

Considerai que os raios de luz estão em movimento. Se eles se desviam, mudando seu curso, deve ser em virtude de alguma lei primitiva, e deve acontecer com a luz o mesmo que ocorre com todos os corpos da mesma pequenez da luz, considerando as outras coisas iguais (...). Há, portanto, uma força qualquer que age entre os corpos e a luz (Voltaire, 1996 [1738], p. 113). 
Apesar de fazer referência constante a Newton, esse último considerou a existência de forças entre a luz e a matéria novamente de forma superficial e sem muitos detalhes. Nos segundo e terceiro livros do Óptica, suas ideias espalham-se em meio a outras. Por exemplo, na oitava proposição do segundo livro, logo após afirmar que a causa da reflexão não era o choque da luz com os corpos, comenta sobre o poder do corpo sobre a luz. Esse poder estaria espalhado por toda a superfície do corpo e agiria sobre a luz sem a necessidade de contato imediato. Na nona proposição, define esse poder como uma "força, exercida variadamente em variadas circunstâncias", como a reflexão e a refração alternadas e a reflexão total da luz (cf. Newton, 1996 [1704], p. 203). Na décima proposição, busca explicar como essa força agiria, utilizando, porém, apenas exemplos de uma refração ideal - na qual não haveria raio refletido - e da reflexão total, não discutindo o que ocorreria em casos reais, nos quais também há raios sendo refletidos. A hipótese da existência de forças agindo a distância entre luz e matéria é retomada por Newton nas "Questões" do terceiro livro do Óptica.

Não têm as pequenas partículas dos corpos certos poderes, virtudes ou forças por meio dos quais elas agem a distância não apenas sobre os raios de luz, refletindo-os, refratando-os e inflectindo-os, mas também umas sobre as outras, produzindo grande parte dos fenômenos da natureza? (Newton, 1996 [1704], p. 274).

Embora Newton não tenha se aprofundado sobre a existência de forças entre a luz e a matéria no Óptica, ${ }^{\mathbf{6}}$ Voltaire a considerou como algo real que "não podemos duvidar de que essa tendência existe (...). Ora, essa força age necessariamente em linha perpendicular, que é o caminho mais curto" (Voltaire, 1996 [1738], p. 113). O filósofo francês apresentou vários argumentos para embasar a atração entre a matéria e a luz. Um deles, em particular, destaca-se, pois se refere ao artigo "Nova teoria da luz e das cores”, no qual Newton não discutiu a interação entre a luz e a matéria.

(...) os raios se quebram em direção à perpendicular, não quando passam de um meio mais fácil para um meio mais resistente, mas quando passam de um meio menos atraente para um meio que atrai mais. Observai que nunca se deve entender por essa palavra "atraente" a não ser o ponto para o qual se dirige essa força reconhecida, uma propriedade incontestável da matéria, muito sensível entre a luz e os corpos. Que se considere que, desde 1672, quando Newton mostrou essa

\footnotetext{
6 Isso pode ser explicado pelo processo de redação e finalização do Óptica. Newton considerou destinar um livro inteiro à relação entre a luz e os corpos por meio de forças, mas abandonou essa ideia ao perceber que não teria tempo para concluí-lo (cf. Westfall, 1980, p. 521; Shapiro, 1992; Hall, 1993, p. 87).
} 
atração, nenhum filósofo pôde imaginar uma razão plausível desse desvio da luz (Voltaire, 1996 [1738], p. 114).

Em trechos posteriores, Voltaire afirmou que a separação da luz branca em raios coloridos ao passar por um prisma seria causada pelas diferentes atrações do vidro sobre cada raio colorido, que teriam massas diferentes, reinterpretando o artigo de 1672 , de modo a reforçar sua argumentação a favor da atração entre a luz e a matéria.

As críticas recebidas por Newton ao trabalho de 1672 foram amenizadas e ridicularizadas por Voltaire. Para ele, os críticos foram obrigados a ceder devido às evidências a favor da concepção newtoniana, pois ela teria sido construída a partir da experimentação, e não meramente de suposições. Voltaire aproveita ainda para repreender seus conterrâneos que não aceitavam as ideias newtonianas.

No começo, o que se escreveu de mais leve contra Newton é que seu sistema era uma hipótese. Mas o que é uma hipótese? Uma suposição. Na verdade, podem-se chamar de suposição fatos tantas vezes demonstrados? Será porque se nasceu na França que se tem vergonha de aceitar a verdade das mãos de um inglês? Esse sentimento seria indigno de um filósofo. Para qualquer um que pense, não há nem francês nem inglês: aquele que nos instrui é nosso compatriota (Voltaire, 1996 [1738], p. 123).

Em seguida, Voltaire explica as cores dos corpos fazendo um paralelo com as discussões de Newton sobre os anéis de cores em películas finas, conhecidos atualmente como "anéis de Newton". ${ }^{7}$ Newton havia estudado as cores nos primeiro e segundo livros do Óptica, sendo que no segundo livro tentou unificar a explicação das cores dos corpos naturais com as cores formadas em películas finas. Para ele, os corpos refletiam determinadas cores de acordo com o tamanho das partículas que os compunham e supôs que um corpo exibia uma determinada cor porque era composto por corpúsculos de um determinado tamanho que refletiriam essa cor. Portanto, um anel da mesma cor seria formado por uma película da mesma espessura dos corpúsculos que o constituem.

As partes transparentes dos corpos, de acordo com seus vários tamanhos, refletem raios de uma cor e transmitem os de outra pela mesma razão pela qual as

\footnotetext{
7 Os anéis podem ser visualizados, por exemplo, em um sistema de duas lentes pressionadas uma contra a outra ou em bolhas de sabão. Atualmente, esse fenômeno é explicado como resultado da interferência entre as ondas luminosas refletidas na primeira e na segunda superfícies do filme fino de ar entre duas lentes ou da película de sabão em uma bolha.
} 
Voltaire e Algarotti: divulgadores da óptiga de Newton na Europa do século xviit

lâminas finas ou as bolhas refletem ou transmitem esses raios. E considero esta a razão de todas as suas cores (Newton, 1996 [1704], p. 192-3).

Newton fornece vários exemplos para reforçar essa ideia, como as cores em penas de pássaros, teias de aranha, folhas, pós de tinta, entre outros. No Óptica, Newton não havia discutido por que haveria uma relação entre o tamanho dos corpúsculos de matéria e a espessura das películas com as cores que refletem. Esse tipo de especulação está presente em outro texto, "Hipótese da luz" ("Hipothesis of light"), lido na Royal Society em 1675 e publicado apenas no século xviı. ${ }^{8}$ Apesar disso, Voltaire atribuiu a causa das cores dos corpos à existência de um poder sobre os raios de luz.

Os corpos mais apropriados para transmitir os raios vermelhos, e cujas partes absorvem ou deixam passar os outros raios, serão vermelhos, e assim por diante. Isso não quer [dizer] que as partes desses corpos de fato reflitam os raios vermelhos, mas sim que há um poder, uma força até aqui desconhecida que reflete esses raios junto às superfícies e no seio dos poros dos corpos (Voltaire, 1996, p. 132).

Para explicar os anéis de cores em películas finas, por sua vez, Newton fornece uma série de explicações diferentes, tais como a força entre a luz e os corpos, a densidade do éter e, por fim, a teoria de estados de fácil transmissão e fácil reflexão. Os aspectos envolvidos nos estudos de Newton sobre esse fenômeno presentes no segundo livro do Óptica e em trabalhos anteriores e os modelos explicativos que ele elaborou são controversos e complexos (cf. Shapiro, 1993; Moura, 2008); por isso, concentrar-nos-emos no último deles, a teoria dos estados.

A teoria dos estados da luz foi discutida no final do segundo livro do Óptica. Segundo Newton, os estados seriam propriedades originais da luz - assim como as cores - e explicariam as tendências dos raios a serem refletidos ou refratados pelas películas finas, produzindo as diferentes cores dos anéis.

O motivo pelo qual as superfícies de todos os corpos espessos transparentes refletem parte da luz que sobre eles incide e refratam o restante é que alguns raios, em sua incidência, estão em estado de fácil reflexão e outros em estado de fácil transmissão (Newton, 1996 [1704], p. 212).

8 Esse texto foi inicialmente elaborado como uma resposta às críticas de Robert Hooke $\left(1635^{-1703)}\right.$ ao artigo de 1672. O texto foi lido na Royal Society em dezembro de 1675 . Em 1757, ele foi finalmente publicado no livro The history of the Royal Society of London, escrito por Thomas Birch (1705-1766). 
Em relação à origem e natureza dos estados, Newton desenvolve uma argumentação contraditória, ora afirmando que os estados estariam presentes desde a primeira emissão dos raios, ora afirmando que eles seriam causados pela interação entre a luz e os corpos. Nas "Questões", ele chegou a especular que a origem dos estados estaria na força de atração exercida pelos corpos sobre a luz, o que assinala sua incerteza sobre a natureza dessa propriedade da luz.

Provavelmente, os seguidores de Newton estavam cientes do fato de ele ter explorado várias hipóteses diferentes, muitas vezes conflitantes entre si, e claramente ignoraram as hipóteses que não se enquadravam na abordagem mecânica dos fenômenos ópticos, como os estados da luz. Voltaire adotou atitude semelhante no Elementos. Ao priorizar as explicações newtonianas baseadas na existência de força atrativa entre a luz e os corpos e ao deixar de lado outras hipóteses também exploradas por Newton, muitas vezes de forma bem mais aprofundada, como é o caso dos estados da luz, Voltaire buscou divulgar as partes da óptica de Newton que se adequavam a um modelo mecânico para a luz e que concordavam com o ideal da época de ressaltar a importância da experimentação para a filosofia natural. Por estar envolvido nesse contexto, ideias muito complexas, controversas ou com evidente caráter hipotético não foram disseminadas por ele.

Voltaire parece admitir, em carta a remetente desconhecido, a existência de aspectos inconclusivos acerca da força entre os corpos e os raios de luz.

Teria tido a hora, senhor, de responder mais cedo, sem as doenças contínuas que exercitam minha paciência mais do que Newton exercita meu espírito. Creio que vossas dúvidas teriam provocado essas doenças no próprio Newton. Dizeis que é uma pena que ele não se tenha explicado mais claramente a respeito da razão pela qual a força atrativa torna-se frequentemente repulsiva, e sobre a força pela qual os raios de luz sejam lançados com tão prodigiosa rapidez.

Eu vos exponho minhas dúvidas, senhor, com a mesma franqueza com a qual me comunicastes as vossas. Felicito-vos por cultivar a filosofia, que nos deve ensinar a duvidar de tudo aquilo que não é do domínio das matemáticas e da experiência (Voltaire, 1996 [1704], p. 144-5). ${ }^{9}$

9 Na edição brasileira de 1996 do Elementos da filosofia de Newton, foi publicada uma carta da qual retiramos a citação, mas não há informações na edição brasileira sobre quando a carta foi escrita ou a quem se destinava. Pesquisamos também a edição inglesa (cf. Voltaire, 1738), e a Oeuvres complètes de Voltaire (1785). Além de notarmos algumas diferenças no conteúdo das três versões do Elementos, encontramos a carta apenas na Oeuvres. Com isso, concluímos que ela provavelmente foi escrita alguns anos após a publicação do Elementos, e não compunha seu texto original. 
Voltaire e Algarotti: divulgadores da óptiga de Newton na Europa do século xviit

Nessa carta, em uma espécie de confissão particular, Voltaire adotou uma postura mais contida, reconhecendo as limitações de algumas explicações newtonianas, o que pode ser interpretado como um indicativo de que talvez alguns newtonianos possam ter admitido os limites de suas ideias sobre a luz, principalmente sobre a existência de forças entre a luz e a matéria. No entanto, expuseram em suas obras apenas alguns aspectos da óptica newtoniana, deixando propositadamente de criticar ou mencionar as partes problemáticas.

\section{O texto de Algarotti sobre Newton}

Na Itália, ao contrário da França, a recepção à óptica de Newton foi menos problemática, uma vez que o cartesianismo não era tão influente. Newton mantinha boas relações com figuras italianas notáveis da época, tais como Francesco Bianchinni (1662-1729) e Guido Grandi (1671-1742), a quem ele inclusive enviou cópias do então recém publicado Óptica. Além disso, a edição em latim do livro, publicada em 17o6, foi rapidamente lida e estudada. No curso das décadas seguintes, foram publicados no país vários manuais newtonianos, baseados principalmente na obra de outros popularizadores, como 'sGravesande e Pemberton (cf. Casini, 1995, p. 178, 181, 184, 205). Dentre os poucos críticos da óptica de Newton no país estava Giovanni Rizzetti (1675-1751), que em 1722 publicou um texto negando a validade dos experimentos newtonianos, em grande parte, influenciado pelas conclusões de Mariotte (ver a nota 2).

Nesse contexto, Francesco Algarotti, pupilo do então presidente do Istituto dell'Academia delle Scienze, Francesco Zanotti (1692-1777), realizou vários experimentos de óptica em Bolonha, entre 1728 e 1729, em um provável movimento para contrapor-se às críticas de Rizzetti (cf. Casini, 1995, p. 204; Hall, 1993, p. 213). Nos anos que se seguiram, Algarotti continuou sua defesa do modelo newtoniano, porém, dessa vez, de forma mais informal.

Algarotti escreveu uma das obras sobre Newton mais populares e lidas na Europa do século xvıII, O newtonianismo para as damas ou diálogos sobre a luz e as cores (1739c), publicado em italiano em 1737 . O livro contribuiu para a construção de uma imagem idealizada do legado newtoniano, especialmente de sua teoria da luz e das cores. Algarotti foi um dos primeiros italianos a estudar a óptica newtoniana em meados da década de 1720 e, além das influências de Zanotti, foi bastante influenciado pela convivência no castelo de Émilie du Châtelet em 1735, no mesmo período em que Voltaire habitou o local.

Em seu livro, Algarotti buscou ilustrar a superioridade, beleza e perfeição da filosofia natural newtoniana, ao mesmo tempo em que criticou fortemente as teorias de 
outros pensadores, especialmente Descartes. As primeiras cópias foram publicadas em 1737 e tiveram sucessivas edições até $175^{2}$, quando Algarotti parece ter finalmente completado seu trabalho (cf. Mazzotti, 2004, p. 123). Ao longo dessas duas décadas entre a primeira e a última edição, O newtonianismo para as damas difundiu-se por toda a Europa, divulgando em várias línguas a síntese newtoniana entre os leigos do continente interessados na ciência (cf. Casini, 1995, p. 222). A versão francesa, traduzida por Loius-Adrien Du Perron de Castera (1705-1752) em 1738, foi uma das mais populares. A tradução não agradou Algarotti, pois Castera incluiu vários argumentos científicos incorretos e tentou em alguns momentos resgatar o cartesianismo, duramente criticado pelo italiano (cf. Mazzotti, 2004, p. 123). Em inglês, o texto de Algarotti apareceu pela primeira vez em 1739, traduzido por Elizabeth Carter (171 $7^{-}$ 1806) (cf. Algarotti, 1739a; 1739b). ${ }^{10}$

O newtonianismo para as damas representa, assim como o Elementos, a tendência de apresentar uma filosofia natural newtoniana mais acessível ao público leigo no século xvıı. Cabe dizer que a expressão "para as damas" não restringiu o livro apenas às mulheres. Essa era uma forma comum de nomear trabalhos que não continham cálculos e raciocínios matemáticos complexos e que poderiam ser lidos por pessoas cultas de ambos os sexos (cf. Hutton, 2004, p. 186).

O livro apresenta seis diálogos entre uma marquesa (ou dama) e um cavalheiro. Enquanto o cavalheiro é o porta-voz de Algarotti, a dama é retratada como uma charmosa e volúvel mulher, cujas ideias mudam facilmente pela condução do cavalheiro. Esse retrato não difere muito da forma coadjuvante e ilustrativa pela qual a mulher era representada no período (cf. Badinter, 2003, p. 27-36; Mazzotti, 2004, p 127-32). ${ }^{\mathbf{1 1}}$ Essa imagem da marquesa não cativou Émilie du Châtelet, que criticou a frivolidade do texto de Algarotti e sua dedicatória a Bernard de Fontenelle (1657-1757), um opositor à teoria da gravitação universal de Newton (cf. Hutton, 2004, p. 197).

\footnotetext{
10 Essa versão também recebeu críticas de Algarotti. Na Advertência da edição em italiano de 1739, ele afirma que gostaria que o texto fosse tão fiel e puro quanto sua tradutora (cf. Algarotti, 1739c, Avertimento). No intuito de compreender melhor o pensamento de Algarotti, consultamos cinco edições do 0 newtonianismo para as damas. Além da versão em inglês de 1739, a qual utilizamos como base para as citações, pesquisamos as edições em italiano de 1737 , 1739 e 1746 (cf. Algarotti, 1737; 1739c; 1746), a inglesa de 1742 (cf. Algarotti, 1742a; 1742b) e a francesa de ${ }_{1739}$ (Algarotti, $1739 d$ ). Há algumas diferenças significativas entre elas em relação a conteúdo e estrutura, que serão apontadas oportunamente. Para um exame mais detalhado sobre elas, sugerimos as leituras de Hutton (2004) a respeito das edições em italiano, e Miller (2013) acerca das edições em inglês.

11 Na edição em inglês de 17422, o papel da marquesa muda um pouco em relação à versão original italiana. Ao contrário da mulher fútil, a marquesa interage intelectualmente com o cavalheiro em nível de igualdade; o que se deve ao fato de essa versão ter sido baseada em uma mescla da edição inglesa de 1739 com a edição francesa de 1738 , feita por Castera. Embora Algarotti pudesse ter certo controle das versões italianas, o mesmo não se pode dizer das edições em outras línguas (cf. Miller, 2013, p. 199, 202).
} 
Os diálogos começam com o cavalheiro afirmando que a história que irá contar será "inteiramente filosófica e composta de certas conversas que eu tive com uma educada senhora sobre o assunto da luz e das cores" (Algarotti, 1739a, p. 2). O interesse da marquesa pela óptica foi motivado pelo fato de o cavalheiro ter feito referência à obra de Newton como a "pintura newtoniana" (Algarotti, 1739a, p. 11) e por uma dúvida sobre a expressão "luz sétupla" (luce settemplice), traduzida para o inglês como seven-fold light, presente em versos endereçados à filósofa natural italiana Laura Bassi (1711-1778).

A composição de sete luzes

de onde todo o charme das cores se espalha

e forma a alegre variedade das coisas (Algarotti, 1739a, p. 11). ${ }^{\mathbf{1 2}}$

A marquesa insiste, então, para que o cavalheiro discuta mais sobre as expressões "luz sétupla" e "pintura newtoniana" (Algarotti, 1739a, p. 11). Não haveria ninguém melhor que o próprio autor do poema para explicar essas questões a ela. O cavalheiro resiste no início, porém, após muita insistência da marquesa, começa a discutir alguns experimentos com prismas feitos por Newton, chegando à conclusão de que "de acordo com a opinião de Sir Isaac Newton (...) todo raio de luz é composto de um número infinito de outros raios" (Algarotti, 1739a, p. 13). A marquesa mostra-se deslumbrada pelas ideias newtonianas.

(...) e como tudo que você falou foi dito com um ar de seriedade e tamanha confiança, sem escrúpulos, de acordo com a opinião de Sir Isaac Newton, ou melhor, como a coisa é realmente, deixou-me com um extremo desejo de tornar-me uma newtoniana (Algarotti, $1739 a$, p. 15).

$12 \mathrm{O}$ trecho original em italiano é o seguinte:

O dell'aurata

luce settemplice

$i$ varioardenti, e misti almi color (Algarotti, 1737, p. 6).

Não há diferenças entre as outras edições em italiano pesquisadas (cf. Algarotti, 1739; 1746). Entretanto, na versão em inglês de 1742, o poema está escrito desta forma:

That seven-fold light, that Golden ray,

shot forth from the bright orb of the day,

in whose direct transparent line,

united, all the colours shine,

whose beam, as thro' the universe it burns,

all objects shews, and while it shews, adorns (Algarotti, 174,2a, p. 11-2).

O trecho é muito similar ao presente na edição em francês (cf. Algarotti, 1739d, p. 10), o que reforça a tese de Miller (2013) de que a versão inglesa de 1742 é baseada na tradução de Castera. 
O desejo da marquesa certamente era semelhante ao de muitos outros leigos em filosofia natural no século xvıII. A eles estava sendo oferecida uma versão que reforçava a ideia de uma nova filosofia natural apoiada em evidências experimentais, bem diferente das ideias construídas pelos antigos sem embasamento experimental e consideradas inferiores por isso.

A curiosidade da marquesa sobre os fenômenos da luz e das cores parecia só aumentar. O cavalheiro, então, decide iniciar um longo diálogo sobre a filosofia natural, pois achava "necessário dar a ela alguma ideia geral disso, antes de proceder com a explicação do sistema newtoniano" (Algarotti, 1739a, p. 17). Ele faz, assim, uma exposição inicial sobre o desenvolvimento da filosofia natural nos últimos séculos, destacando o papel de Aristóteles e ressaltando que não se faziam experimentos e observações na Antiguidade. Para o cavalheiro, a admiração exagerada aos antigos "foi a causa para que o conhecimento em física tivesse tido pouco ou nenhum progresso até a última época" (p. 27). Nesse período, teriam surgido os "mártires da razão", em especial, Galileo Galilei (1564,-164,2), a quem Algarotti dedica várias páginas.

Para o cavalheiro, Galileo poderia ser chamado de "czar da filosofia natural" (Algarotti, 1739a, p. 29). Classificação semelhante não poderia ser atribuída a Descartes, já que

como então poderia Descartes, por exemplo, que foi o autor chefe dessa aventurosa facção de filósofos, fazer um sistema racional sobre a luz e as cores, quando ele era totalmente ignorante de várias de suas características, as quais Sir Isaac Newton descobriu depois por observações? (Algarotti, 1739a, p. 32-3).

Inicialmente, o cavalheiro explica, a partir da perspectiva cartesiana, a propagação da luz, a formação das cores e os fenômenos da refração e da reflexão. Ele também aborda outros tópicos da óptica, tais como o funcionamento do olho humano, do telescópio e do microscópio. Após o longo diálogo, a marquesa mostra-se admirada e satisfeita com o conhecimento adquirido sobre as teorias de Descartes.

Eu percebo, disse a marquesa, que tenho algum direito de chamar-me de filósofa. Eu tenho minha mente cheia de vórtices (...). Preciso de algo mais para me tornar uma filósofa completa? (Algarotti, 1739a, p. 205-6).

Contudo, em seguida, o cavalheiro a alerta sobre os problemas do sistema cartesiano: "não percebes que a filosofia que tanto aprecias precisa de uma reformulação" (Algarotti, 1739a, p. 206). As palavras do cavalheiro deixam a marquesa confusa: "isso está desconcertando minhas ideias" (Algarotti, 1739a, p. 207). Surpresa, a marquesa 
mostra sua insatisfação. "Eu entendo isso muito bem (...), mas suplico-lhe, pelo amor à filosofia, nunca mais mencionar esses vórtices para mim" (Algarotti, 1739a, p. 213).

A estratégia de Algarotti, inicialmente discutindo aspectos gerais da filosofia natural e posteriormente analisando criticamente as teorias de Descartes, para então introduzir as ideias newtonianas, visava mostrar a incapacidade dos filósofos naturais anteriores a Newton - especialmente Descartes - em tratar a luz e os fenômenos ópticos. Para Algarotti, faltavam-lhes as verdades obtidas por Newton com o uso da experimentação. O tom adotado por ele para descrever a filosofia natural de Descartes é o mesmo de Voltaire. Podemos perceber que ambos, em suas obras, buscaram desqualificar explicitamente as concepções cartesianas, atribuindo vários erros ao francês, no intuito de reduzir sua importância para a filosofia natural do século xvıı e, consequentemente, exaltar as realizações newtonianas.

Nos dois diálogos seguintes, Algarotti trata de aspectos gerais da óptica newtoniana, tais como os experimentos com prismas e a ideia de heterogeneidade da luz branca, buscando sempre reforçar a importância do trabalho realizado por Newton.

Este é um mundo inteiramente novo, enriquecido com as mais brilhantes verdades, descobertas somente por Newton, pois não há o menor traço de qualquer filósofo que tenha aparecido antes dele. Seu tratado de óptica, produto de trinta anos de estudo e pesquisa, é um excelente modelo da verdadeira filosofia (Algarotti, 1739b, p. 18).

Assim como Voltaire, Algarotti buscou ressaltar as contribuições de Newton para uma filosofia natural baseada na experimentação e no uso do método indutivo. Com frequência, ele afirma que Newton "provou por experimentos" suas ideias (Algarotti, 1739b, p. 76). Argumentos a favor do uso da experimentação na filosofia natural são encontrados nas críticas de Algarotti ao uso exagerado da imaginação. Em diversos outros trechos de $O$ newtonianismo para as damas, ele apresenta as críticas do cavalheiro à marquesa, por ela imaginar demais e por ter "alguns resquícios de cartesianismo" (Algarotti, 1739 b, p. 140). Algarotti retrata a óptica newtoniana como sendo uma representante da verdadeira filosofia, construída a partir da experimentação, observação e do conhecimento puro e correto sobre a luz e seu comportamento, seguindo a forma como o próprio Newton via sua obra. Após ouvir a explanação do cavalheiro, a marquesa diz:

nós podemos afirmar, então, respondeu a Marquesa, que assim como tudo aquilo que Midas tocou foi transformado em ouro, do mesmo modo tudo que Sir Isaac Newton manejou tornou-se demonstração (Algarotti, 1739b, p. 44,-5). 
Nos diálogos subsequentes, Algarotti aborda a questão da imutabilidade dos raios coloridos que surgem após a passagem de luz branca por um prisma. Pelas palavras do cavalheiro, ele primeiramente discute a ideia de modificação da luz branca. Essa concepção era aceita por grande parte dos filósofos naturais do século xvII, entre eles Robert Hooke $\left(1635^{-1}\right.$ 1703) e Huygens. Em geral, eles acreditavam que a luz branca era simples e homogênea, e que o prisma agia sobre ela, produzindo as cores. Segundo Algarotti,

Sir Isaac Newton mostrou a falsidade dessa opinião, e demonstrou que um raio, por exemplo, vermelho, bem separado de todo o resto, irá constantemente manter sua cor não importando a refração ou a reflexão que sofrer (...) nós devemos concordar que a refração não tem participação na produção de cores e abandonar o antigo sistema de modificação; e todos os seus ilusórios sonhos desaparecerão ao abrirmos a manhã da verdade newtoniana (Algarotti, 1739b, p. 63-4).

Contudo, ao contrário do que Algarotti faz parecer, essa questão não foi facilmente resolvida por Newton. Na época da publicação do artigo "Nova teoria da luz e das cores”, em 1672, essa proposição foi alvo de intensas críticas por aqueles que defendiam a ideia da modificação ou não obtiveram os mesmos resultados a partir da descrição de Newton. O estabelecimento de que as cores são propriedades originais da luz branca implicava a realização de uma série de experimentos encadeados em uma complexa argumentação bem como o uso de argumentos metodológicos, que só foram apresentados de forma coerente no Óptica, anos depois (cf. Martins \& Silva, 2001).

Assim como Voltaire, Algarotti reforça o papel desempenhado pela ação de forças entre os corpos e os corpúsculos de luz, conferindo-lhes um protagonismo bem maior do que o atribuído pelo próprio Newton.

A atração é a chave de toda a filosofia, a grande engrenagem que atua sobre a estrutura da natureza; a força universal e misteriosa descoberta e calculada por Sir Isaac Newton (...). A atração está longe de ser um segredo; ela é uma qualidade extremamente evidente da matéria, da qual claramente depende a explicação da difração, a própria refração e inumeráveis outras coisas (Algarotti, 173gb, p. $137^{-8)}$.

A marquesa, entretanto, teve dificuldades em entender a atração entre os corpos e a luz: 
Voltaire e Algarotti: divulgadores da óptiga de Newton na Europa do século xviil

Entendo, ou acho que entendo, como os raios de luz são diferentemente refrangíveis. Isso dentre outras coisas é muito inteligível. Mas que os corpos devem atrair a luz (...) parece muito difícil conceber (Algarotti, 1739b, p. 140).

Segundo o cavalheiro, a dúvida da marquesa seria causada pela influência do cartesianismo em sua mente. Para ele, a atração poderia ser verificada a partir da observação, principalmente dos fenômenos celestes. O diálogo seguinte, o sexto, é dedicado inteiramente à discussão da atração e de sua aplicação na óptica. Para comprovar a existência da atração, o cavalheiro discute a interação entre os planetas e o Sol. Todas as órbitas seriam explicadas perfeitamente pela concepção newtoniana de ação a distância e Algarotti buscou enfatizar a relevância da ideia de que a força entre os corpos diminui com o inverso do quadrado da distância $\left(1 / \mathrm{r}^{2}\right)$. Em certo momento, ele chega a especular uma possível relação entre esse conceito de atração com a intensidade da luz.

O decréscimo da força atrativa, no que diz respeito à luz, é demonstrado por um experimento muito fácil, o qual podemos fazer esta noite, se você não estiver já muito cansada de filosofia e experimentos (Algarotti, 1739b, p. 169).

O experimento consistia em colocar um livro ou uma carta contra a luz de uma vela acesa a certa distância, de modo que não se enxergasse muito bem as letras das páginas. Posicionando-se a uma distância duas vezes maior que a primeira, a "força da luz" seria quatro vezes menor (cf. Algarotti, 1739b, p. 169). Nessa situação, somente seria possível enxergar as letras do mesmo modo que antes, se a luz fosse quadruplicada, ou seja, se adicionássemos mais três velas ao lado da vela original. No Óptica, Newton não abordou experimentos semelhantes a esse, tampouco esse tipo de relação, que é bastante imprecisa. $^{\mathbf{1 3}}$

Em trechos seguintes, o cavalheiro explora mais profundamente a hipótese de atração em fenômenos da luz e das cores. Ele questiona se a ocorrência da refração não seria uma evidência da atração.

(...) não é a refração um efeito dessa força atrativa? Ela não surge a partir disso, de que os meios pelos quais a luz passa estão imbuídos com essa força em maior ou menor grau, de acordo com a maior ou menor densidade do meio? Do contrá-

13 A ideia de que a intensidade da luz diminuía em uma proporção inversa ao quadrado da distância era considerada pelo menos desde os estudos de Johannes Kepler (1571-1630) no início do século xviı (cf. Mach, 20o3, p. 13; Darrigol, 2012, p. 31-2, 110). Entretanto, Algarotti uniu essa ideia ao conceito de atração entre os corpos, que também incluía a proporção inversa ao quadrado da distância. Esse tipo de consideração não existia antes de Newton. 
rio, a imensa força da Terra, a qual atrai toda coisa a ela mesma, tornaria impossível qualquer prisma, mesmo se fosse tão grande quanto o pico Tenerife, atrair o menor raio de luz (Algarotti, 1739 b, p. 210). ${ }^{\mathbf{1 4}}$

O cavalheiro argumenta que o raio de luz seguiria seu caminho sem desviar-se em sua passagem por um meio, pois seria atraído igualmente para todos os lados. Caso se deparasse com um meio mais denso, ele declinar-se-ia por influência desse meio. $\mathrm{O}$ mesmo poderia ser evidenciado pela passagem de um raio de um meio mais denso para um menos denso, ocasionando inclusive a reflexão total. Na seção anterior, comentamos que Newton utilizou um argumento semelhante no Óptica, mas não o desenvolveu satisfatoriamente e tampouco abordou o fato de que os raios de luz são parcialmente refletidos e refratados quando passam do ar para o vidro, por exemplo.

Algarotti parece estar ciente desse problema e propõe a hipótese da existência de uma força repulsiva entre os raios de luz e os meios materiais. Pelas palavras do cavalheiro, afirma que as forças de atração e repulsão teriam a mesma natureza, ou seja, seriam a mesma força atuando em diferentes circunstâncias. A marquesa, obviamente, espanta-se:

O que? disse ela. Você fala [que] a força atrativa e repulsiva são a mesma coisa? Uma age diretamente contrária à outra, uma vez que a primeira atrai e a outra repele (Algarotti, 1739 b, p. 224).

14 Nas edições pesquisadas para esta análise, encontramos algumas variações para este trecho. Na edição original em italiano, de 1737 , está descrito o seguinte logo após a pergunta:

E questa forza non fará ella maggiore della gravità? (Algarotti, 1737, p. 276).

Na edição em inglês de 1739, como mencionamos, esse trecho foi suprimido. O mesmo acontece na versão em italiano de 1739 (cf. Algarotti, ${ }_{7739}$ c, p. 270). Contudo, na versão inglesa de 1742, o trecho aparece como no original italiano de 1737 :

(...) and won't this force be superior to gravitation? (Algarotti, 174,2b, p. 190-1).

Na edição em italiano de 174,6 o trecho também foi suprimido (cf. Algarotti, 174,6, p. 311). Acreditamos que Algarotti tenha inicialmente pensado em argumentar sobre as razões pelas quais a força gravitacional da Terra não causaria efeito na propagação dos raios de luz. Parece-nos que a única maneira de ele resolver essa questão seria especular inicialmente que a força do meio sobre a luz é maior do que a gravitação, a fim de, possivelmente, superar o efeito dessa última. É provável que nas edições seguintes ele tenha preferido não se ater mais a essa questão, apenas mencionando a existência de uma força atrativa dos corpos sobre a luz. Por sua vez, ainda resta a dúvida do motivo de a frase não aparecer na versão inglesa de 1739 , uma vez que se admitiu que ela estava baseada na versão original de 1737 . Possivelmente, ou Carter ou o editor (Edward Cave) perceberam a contradição iminente se a pergunta fosse colocada. 
Para esclarecer a dúvida da marquesa, o cavalheiro diz existirem analogias entre as duas forças. Segundo ele, um corpo que possui maior poder refrator também possui maior poder refletor. Dessa forma, quando os raios passam de um meio menos denso para outro mais denso, eles são ao mesmo tempo refratados e refletidos, e isso é amplificado dependendo das diferenças de densidade.

A marquesa, então, questiona se a reflexão não seria causada meramente pelo choque das partículas de luz com as partículas dos corpos. O cavalheiro responde, em tom irônico, que essa explicação foi dada por Descartes, não por ele. "É Descartes, senhora, que lhe deu essa explicação, não eu. Portanto, você pode ter alguns receios sobre isso" (Algarotti, 1739b, p. 228). No Óptica, Newton foi contra a explicação da reflexão baseada no choque da luz com a superfície dos corpos, defendendo a ideia de um poder existente na superfície do corpo como a causa do fenômeno. Entre seus argumentos estava a impossibilidade das reflexões serem tão regulares devido à dificuldade de polir-se regularmente as superfícies. Como existiriam ranhuras difíceis de serem eliminadas, os raios seriam refletidos irregular e aleatoriamente, formando imagens difusas e imperfeitas (cf. Newton, 1996 [1704], p. 201). O fato de as imagens de objetos refletidos serem iguais aos próprios objetos indicava que as reflexões eram regulares e, portanto, deveriam ocorrer de alguma outra forma que não pelo choque da luz com a superfície do corpo refletor.

Algarotti adota o mesmo argumento de um poder atuando entre a luz e os corpos, ressaltando que, embora essa conclusão fosse difícil de ser assimilada, ela seria provada pela observação, principalmente no caso da reflexão total da luz quando ela passa, por exemplo, do vidro para o ar. Não haveria como explicar porque a luz encontraria mais partículas resistentes a sua propagação no ar do que no vidro. Como a luz era refletida totalmente, isso só poderia ser explicado pela atuação de uma força, no caso, atrativa, do vidro sobre o raio de luz. O cavalheiro resume então suas ideias sobre as forças atrativas e repulsivas.

Em geral, nós podemos afirmar que a força atrativa é a causa da reflexão dos raios quando a luz passa de um meio mais denso para um mais rarefeito; e repulsiva, quando passa de um [meio] mais rarefeito para um mais denso (Algarotti, $1739 \mathrm{~b}$, p. 232-3).

Embora Algarotti tenha indicado que haveria uma analogia entre a força atrativa e a repulsiva e que elas existiriam ao mesmo tempo nos corpos, ele não ofereceu argumentos para justificar a existência de duas causas que produzem efeitos tão diferentes. Para ele, aparentemente, o fato de vermos os raios de luz sendo refletidos e refratados ao mesmo tempo seria uma evidência indubitável da existência de tal força, uma vez 
que foi obtida pela observação e não pela imaginação. No entanto, poderíamos perguntar: como uma força atrativa e uma repulsiva interagem ao mesmo tempo? Elas não se anulariam? Como um mesmo corpo é capaz de exercer simultaneamente dois efeitos contrários um ao outro? Por que alguns raios são influenciados pela força atrativa e outros pela força repulsiva? Todas essas perguntas poderiam ter sido feitas na época. Voltaire chegou a fazer algumas na carta ao final do Elementos. O próprio Algarotti parece ciente disso, uma vez que as palavras da marquesa em um trecho posterior corroboram essa suposição.

Parece muito mais surpreendente, disse a marquesa, que qualquer pessoa possa claramente ver e demonstrar que duas coisas tão opostas como a reflexão e refração deveriam então originar-se da mesma causa; isso, eu confesso, será sempre um espanto para mim (Algarotti, 1739b, p. 238).

Nas "Questões" do Óptica, Newton havia abordado timidamente a existência de um poder repulsivo do corpo.

Visto que os metais dissolvidos em ácidos atraem somente uma pequena quantidade do ácido, sua força atrativa pode alcançar apenas uma distância pequena em relação a eles. E assim como em álgebra, onde as quantidades positivas desaparecem e cessam, ali começam as quantidades negativas, assim também na mecânica, onde cessa a atração, ali deve suceder uma virtude repulsiva. E que tal virtude existe parece decorrer das reflexões e inflexões dos raios de luz. Pois os raios são repelidos pelos corpos, nesses dois casos, sem o contato imediato do corpo refletor ou infletor. Parece decorrer também da emissão da luz, sendo o raio expelido com uma velocidade extremamente grande tão logo é liberado de um corpo brilhante pelo movimento vibratório das partes do corpo e chega além do alcance da atração. Pois a força que é suficiente para fazer com que ele volte atrás na reflexão pode ser suficiente para emiti-lo (Newton, 1996 [1704], p. 286).

Sendo assim, após uma região de atração, existiria uma zona em que o raio seria repelido. Newton não relacionou essas ideias com suas discussões anteriores, especialmente as presentes nas oitava, nona e décima proposições do segundo livro. Algarotti também não as utilizou em sua argumentação.

Logo após a discussão sobre as forças atrativas e repulsivas, o cavalheiro comenta sobre os estados de fácil transmissão e reflexão da luz. Da mesma forma que Voltaire, Algarotti dá a entender que considerava esse conceito ainda não plenamente estabelecido. 
Voltaire e Algarotti: divulgadores da óptiga de Newton na Europa do século xviit

Então vêm os estados de fácil transmissão e reflexão, isto é, o mesmo raio de luz é em um momento transmitido e em outro refletido (...). Mas nós agora chegamos aos confins da natureza, onde nossas ideias se escurecem e se confundem ${ }^{\mathbf{1 5}}$ (Algarotti, 174,2b, p. 216).

Após vários dias de conversa, a marquesa parece finalmente aderir ao pensamento newtoniano e livrar-se dos erros, especulações e excessos de imaginação que, na visão de Algarotti, havia no pensamento do cartesianismo. $\mathrm{O}$ cavalheiro diz à marquesa,

Você já renunciou a seus erros filosóficos (...). A luz do newtonianismo dissipou os fantasmas cartesianos que enganaram seus sentidos. Agora você é realmente uma newtoniana (Algarotti, 1739b, p. 247).

Algarotti construiu uma das defesas mais populares da óptica de Newton na época. Da mesma maneira que o Elementos de Voltaire, O newtonianismo para as damas de Algarotti foi amplamente lido na Europa do século xvıı. No entanto, a primeira edição de 1737 não agradou o Santo Ofício da Igreja Católica. Em 1739, o livro foi condenado ao Index Librorum Prohibitorum, a lista de livros proibidos pelos católicos. Mazzotti (2004) considera que a condenação deu-se em virtude da explícita adesão de Algarotti ao heliocentrismo e do teor erótico de alguns diálogos entre o cavalheiro e a marquesa presentes na primeira edição. Ele comenta sobre as diversas modificações no conteúdo do texto realizadas nas edições seguintes, baseando-se, inclusive, em recomendações da própria Igreja. Essas edições não entraram no Index (cf. Mazzotti, 2004, p. 137-8).

À parte desses fatos que cercaram a obra de Algarotti, ela manteve-se como uma importante defesa e divulgação da óptica de Newton na primeira metade do século xviıI.

\section{ComentáRios finais}

Ao apresentar uma versão da óptica de Newton com forte ênfase nos aspectos experimentais, Voltaire e Algarotti - e muitos outros popularizadores - tiveram um papel relevante na seleção dos conteúdos do que atualmente se entende por óptica newtoniana: a teoria da luz e das cores, a composição da luz branca e a concepção corpuscular

15 Novamente há diferenças entre as edições consultadas. O trecho sobre os estados aparece também na edição italiana de 1737 (Algarotti, 173 7, p. 295) e na edição inglesa de 17422 (Algarotti, 17422b, p. 216). Nas edições italiana de 1739 (Algarotti, 1739 c, p. 286) e de 1746 (Algarotti, 1746, p. 331), essa parte foi suprimida. Possivelmente, Algarotti optou por não mais citar o conceito de estados por sua incompatibilidade com o modelo mecânico para a luz que ele defendeu anteriormente, assim como fizeram Voltaire e outros. 
para a luz. Eles deixaram de abordar ou mencionaram de forma muito superficial aspectos complicados e com pouco apelo experimental do Óptica, como, por exemplo, os estados da luz.

Os trabalhos de divulgação de Voltaire e Algarotti foram escritos em um período no qual a óptica newtoniana ganhou bastante credibilidade entre os filósofos naturais pelo seu conteúdo científico e também pela forma como foram apresentadas no Óptica, entre outras razões, pela escrita em língua vulgar, seguindo uma sucessão de proposições embasadas em experimentos. No processo de popularização, os dois autores reinterpretaram os discursos newtonianos e criticaram fortemente os antecessores de Newton. Ressaltando o papel da experimentação e rechaçando as hipóteses e o pensamento especulativo, Voltaire e Algarotti pintaram um retrato idealizado com nuances de um indutivismo ingênuo das contribuições de Newton para a óptica, algo que ainda hoje permeia o discurso do público leigo em história da ciência.

Breno Arsioli Moura

Centro de Ciências Naturais e Humanas, Universidade Federal do ABC, Santo André, Brasil. breno.moura@ufabc.edu.br

\section{Cibelle Gelestino Silva} Instituto de Física de São Carlos, Universidade de São Paulo, Brasil. cibelle@ifsc.usp.br Voltaire and Algarotti:
diffusers of Newton's optics in Europe in the eighteen century

\section{ABSTRACT}

In the beginning of 18th century, Newton published his main work about light and colors, the Opticks. Impregnated by an inductive perspective, the book became the major reference for the studies about light and colors, being widely popularized by Newton's followers. In this article, we analyze how two important works contributed to this process of popularization and also what image of science they intended to propagate: Voltaire's Elements of Newton's philosophie and Algarotti's Sir Isaac Newton's philosophy explain'd for the use of the ladies. We will be notice that both authors distorted the content of the Opticks, in order to propagate an idealized image of Newtonian ideas and natural philosophy itself.

KeYwords $・$ Newton. Voltaire. Algarotti. Optics. 18th century. Popularization of science. 
Voltaire e Algarotti: divulgadores da óptiga de Newton na Europa do século xviit

\section{REFERÊNCIAS BIBLIOGRÁFICAS}

Algarotti, F. Il newtonianismo per le dame ovvero dialoghi sopra la luce e i colori. Napoli: [s.n.], ${ }_{17} 37$.

Sir Isaac Newton's philosophy explain'd for the use of the ladies in six dialogues on light and colours.

London: [s.n.], 1739a. v. 1.

. Sir Isaac Newton's philosophy explain'd for the use of the ladies in six dialogues on light and colours.

London: [s.n.], 1739 b. v. 2.

.Il newtonianismo per le dame, ovvero dialoghi sopra la luce, i colori, e l'attrazione. Napoli: [s.n.], 1739c. . Le newtonianisme pour le dames, ou entretiens sur la lumière, sur les coulers, et sur l'attraction. Paris: [s.n.], $1739 d$.

. Sir Isaac Newton's theory of light and colours, and his principle of attraction, made familiar to the ladies in several entertainments. London: [s.n], 1742a. v.1.

. Sir Isaac Newton's theory of light and colours, and his principle of attraction, made familiar to the ladies in several entertainments. London: [s.n], 174,2b. v.2.

. Il newtonianismo ovvero dialoghi sopra la luce, i colori, e l'attrazione. Napoli: [s.n.], 1746.

Badinter, E. Émilie, Émilie: a ambição feminina no século XVIII. São Paulo: Discurso Editorial/Duna Dueto/ Paz e Terra, 2003.

Bernardo, L. M. Concepções sobre a natureza da luz no século xvin em Portugal. Revista da Sociedade Brasileira de História da Ciência, 19, p. 3-12, 1998.

Bevilacqua, F.; Gianneto, E. \& Matthews, M. R. (Ed.). Science education and culture: the contribution of history and philosophy of science. Dordrecht: Kluwer Academic Publishers, 2001.

Buchwald, J. Z. \& Cohen, I. B. (Ed.). Isaac Newton's natural philosophy. Cambridge: The MIT Press, 2001.

CANTOR, G. N. Optics after Newton: theories of light in Britain and Ireland, 1704-1840. Manchester: Manchester University Press, 1983.

CAsini, P. Newton e a consciência europeia. São Paulo: Editora Unesp, 1995.

Chaudhury, P. J. Newton and hypothesis. Philosophy and Phenomenological Research, 22, 3, p. 344- 53 , 1962.

Cohen, I. B. O método de Newton e o estilo de Newton. In: Cohen, I .B. \& Westrall, R. (Org.). Newton: textos, antecedentes e comentários. Rio de Janeiro: Contraponto/Eduerj, 2002. p. 164-83.

Cohen, I. B. \& Sмiтн, G. E. (Ed.). The Cambridge companion to Newton. Cambridge: Cambridge University Press, 2002.

Cohen, I .B. \& Westrall, R. (Org.). Newton: textos, antecedentes e comentários. Rio de Janeiro: Contraponto/Eduerj, 2002.

Cronk, N. (Ed.). The Cambridge companion to Voltaire. Cambridge: Cambridge University Press, 2009.

Darrigol, O. A history of optics from Greek Antiquity to the nineteenth century. Oxford: Oxford University Press, 2012.

Desaguliers, J. T. An account of some experiments of light and colours, formerly made by Sir Isaac Newton, and mention'd in his Opticks, lately repeated before the Royal Society. Philosophical Transactions, 29, p. $433-47,1716 \mathrm{a}$.

. A plain and easy experiment to confirm Sir Isaac Newton's doctrine of the different refrangibility of the rays of light. Philosophical Transactions, 29, p. 448-52, 1716b.

Dоввs, В. J. T. Newton's alchemy and his theory of matter. Isis, $7^{3}, 4$, p. 511-28, 1982.

Force, J .E. \& Hutton, S. (Ed.). Newton and newtonianism: new studies. New York: Kluwer Academics Publishers, 2004.

Gillispie, G. C. Voltaire. In: 2007 .v. 3 , p. $2565^{-8}$. (Org.). Dicionário de biografias científicas. Rio de Janeiro: Contraponto, . (Org.). Dicionário de biografias científicas. Rio de Janeiro: Contraponto, 2007. v. 3.

Gjertsen, D. The Newton handbook. London: Routledge \& Kegan Paul, 1986. 
GuerLac, H. Newton on the continent. London: Cornell University Press, 1981.

HaKFoort, C. Optics in the age of Euler: conceptions of the nature of light, 1700-1795. Cambridge: Cambridge University Press, 1995.

Hall, A. R. All was light: an introduction to Newton's "Opticks". Oxford: Claredon Press, 1993.

Hankins, T. The influence of Malebranche on the science of mechanics during the eighteenth century. Journal of the History of Ideas, 28, 2, p. 193-210, 1967.

Harman, P. M. \& Shapiro, A. E. (Ed.). The investigation of difficult things: essays on Newton and the history of exact sciences in honour of D. T. Whiteside. Cambridge: Cambridge University Press, 1992.

Hutton, S. Women, science, and newtonianism: Émilie du Châtelet versus Francesco Algarotti. In: Force, J .E. \& Hutton, S. (Ed.). Newton and newtonianism: new studies. New York: Kluwer Academics Publishers, 2004. p. 183-203.

Mach, E. The principles of physical optics. Mineola: Dover, 2003.

Martins, R. A. \& Silva, G. C. Newton and colour: the complex interplay of theory and experiment. In: Bevilagqua, F.; Gianneto, E. \& Matthews, M. R. (Ed.). Science education and culture: the contribution of history and philosophy of science. Dordrecht: Kluwer Academic, 2001. p. 273-91.

Martins, R. A. et al. (Ed.). Filosofia e história da ciência no cone sul: seleção dos trabalhos do $5^{\circ}$ encontro. Campinas: Associação de Filosofia e História da Ciência do Cone Sul, 2008.

. Filosofia e história da ciência no cone sul: seleção dos trabalhos do $6^{\circ}$ encontro. Campinas: Associação de Filosofia e História da Ciência do Cone Sul, 2010.

Mazzotтi, M. Newton for ladies: gentility, gender and radical culture. British Journal for the History of Science, 37,2, p. 119-4,6, 2004.

McGuire, J .E. \& Rattansi, P. M. Newton and the "pipes of Pan". Notes and Records of the Royal Society of London, 21, 2, p. 108-43, 1966.

MilLer, L. Publishers and gendered readership in English-language editions of "Il newtonianismo per le dame". Studies in Eighteenth Century Culture, 42, p. 191-214, 2013.

Moura, B. A. A aceitação da óptica newtoniana no século XVII: subsídios para discutir a natureza da ciência no ensino. São Paulo: Instituto de Física/Faculdade de Educação/ Universidade de São Paulo, 2008.

Moura, B. A. \& Silva, C. C. A teoria dos estados da luz: considerações sobre o papel das hipóteses na óptica newtoniana. In: Martins, R. A. et al. (Ed.). Filosofia e história da ciência no cone sul: seleção dos trabalhos do $5^{\circ}$ encontro. Campinas: Associação de Filosofia e História da Ciência do Cone Sul, 2008. p. 91-9.

. \& __. Forças entre luz e matéria: modelos mecânicos da óptica corpuscular no início do século xviII. In: Martins, R.A. et al. (Ed.). Filosofia e história da ciência no cone sul: seleção dos trabalhos do $6^{\circ}$ encontro. Campinas: Associação de Filosofia e História da Ciência do Cone Sul, 2010. p. 136-42.

Newton, I. Óptica. São Paulo: Edusp, 1996 [1704].

Palter, R. Newton and inductive method. In: (Ed.). The annus mirabilis of Sir Isaac Newton 16661966. Cambridge: The MIT Press, 1970. p. 244,-57.

(Ed.). The annus mirabilis of Sir Isaac Newton 1666-1966. Cambridge: The MIT Press, 1970.

Porter, R. (Ed.). The Cambridge history of science. Cambridge: Cambridge University Press, 2003. v. 4: Eighteenth century science.

Shapiro, A. E. Beyond the dating game: watermark clusters and the composition of Newton's Opticks. In: Harman, P. M. \& Shapiro, A. E. (Ed.). The investigation of difficult things: essays on Newton and the history of exact sciences in honour of D. T. Whiteside. Cambridge: Cambridge University Press, 1992. p. $181-227$.

Fits, passions, and paroxysms. Cambridge: Cambridge University Press, 1993.

Newton's optics and atomism. In: Cohen, I. B. \& Sмітн, G. E. (Ed.). The Cambridge companion to Newton. Cambridge: Cambridge University Press, 2002. p. 227-55. 
Voltaire e Algarotti: divulgadores da óptiga de Newton na Europa do século xviit

Silva, G. G. A teoria das cores de Newton: um estudo crítico do Livro I do Opticks. Dissertação (Mestrado em Física). Campinas, 1996. Instituto de Física Gleb Wataghin, Universidade Estadual de Campinas.

Silva, C. C. \& Martins, R. A. A “Nova teoria sobre luz e cores" de Isaac Newton: uma tradução comentada. Revista Brasileira de Ensino de Física, 18, 4, p. 313-27, 1996.

Silva, C. C. \& Moura, B. A. Science and society: the case of acceptance of newtonian optics in the eighteenth century. Science \& Education, 21, p. 1317-35, 2012.

Sмith, G. E. The newtonian style in Book II of the Principia. In: Buchwald, J .Z. \& Cohen, I. B. (Ed.). Isaac Newton's natural philosophy. Cambridge: The MIT Press, 2001. p. 249-98.

Turnovsky, G. The making of a name: a life of Voltaire. In: Cronk, N. (Ed.). The Cambridge companion to Voltaire. Cambridge: Cambridge University Press, 2009. p. 17-30.

VOLTAIRE, Letters concerning the english nation. London: [s.n.], 1733.

. The elements of Sir Isaac Newton's philosophy. London: [s.n.], 1738.

. Oeuvres complètes de Voltaire. Kehl: Société Litteraire Typographique, 1785. v. 31.

. Elementos da filosofia de Newton. Campinas: Editora da Unicamp, 1996 [1738].

Westrald, R. S. Never at rest, a biography of Isaac Newton. Cambridge: Cambridge University Press, 1980. 